\title{
Study About Mechanical Properties of Fixation Implant in the Case of Tibia Fracture and Patient Rehabilitation
}

\author{
ELENA MOLDOVAN ${ }^{1}$, VERONICA MINDRESCU ${ }^{*} *$ CORINA CIUPILAN ${ }^{2 *}$, STEFAN SELARU $^{2}$, LAURIAN LUCIAN FRANCU ${ }^{2 *}$, \\ DIANA COTOROS ${ }^{1}$ ANGELA REPANOVICI ${ }^{1}$ \\ ${ }^{1}$ Transilvania University of Brasov (Faculty of physical education and mountain sports), 29 Eroilor, 500036, Braşov, Romania \\ Transilvania University of Brasov (Faculty of Product Design and Environment), 29 Eroilor, 500036, Brașov, Romania \\ 2.Grigore T. Popa University of Medicine and Pharmacy, Faculty of Medicine, 16 University Str., 700115, Iasi, Romania
}

Most of the fixation implants for tibia fracture are made of various metallic alloys based on titanium or even stainless steel. But modern technologies and advanced materials offer endless opportunities of using polymers combined with various fillers to enhance and adjust mechanical properties in order to be as suitable and convenient for any patient.

\section{Keywords: orthopedic implant, tibia fracture fixations, finite element, implantable polymers}

A constant aspect of the biologic environment is the fact that the occurrence of an alien material will trigger a certain response from the host, so biocompatibility of the implant is a considerable concern because it can corrode in a hostile environment, like the human organism. Corrosion leads to material loss, thus weakening the implant resistance or even produces tissue damage.

The implant materials should be flexible and resistant in order to facilitate the fracture fixation, mostly steel and titanium alloys are the usual choices because of their excellent strength and corrosion resistance. If wear resistance is more important, then Co-Cr alloys are sometimes considered.[1] But the costs of the implants are quite high and the wastes become important as the implants can be used only once and the goal is to improve outcome and diminish the costs.[2] The alternative is using implantable polymers, which can be according to the duration in the body, short-term (meaning less than 30 days in contact with the human body) and long-term to permanent.[3] Long-term implantable polymers include biodurable materials like polyethylene and polyketone (PEEK) which have an excellent biocompatibility.[4]The chemical structure of ketones provides stability at high temperatures, resistance to chemical and radiation damage, compatibility with many reinforcing elements, and greater strength than many metals.[5]

There is currently a large range of osteosynthesis materials used for tibia fracture fixation and only the expertise of the orthopedic surgeon and medical engineer allow the adequate selection for every particular situation.[6]

Two different treatment concepts are considered in case of long bones fractures:

- The concept ofrigid fixation with open reduction and internal fixationrepresented by screw and plates (fig.1)

- The concept of elastic fixation where the fractured area is respected by close reduction; a nail is inserted into the neutral axis of the diaphysis and allows a certain elasticity being an undisputed benefit with respect of local condition of bone healing. It is considered to be minimal invasive. (fig.2)

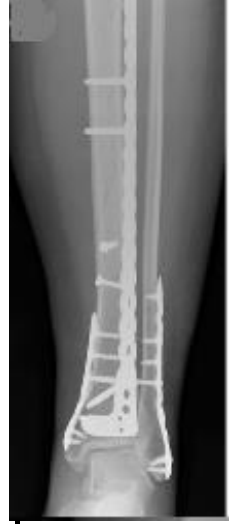

Fig.1 Rigid fixation [7]

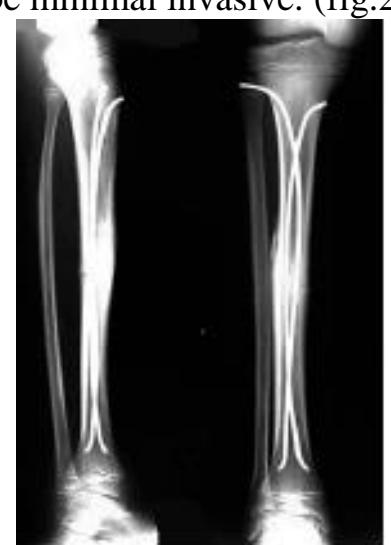

Fig.2 Elastic fixation

\section{Modelling of nail for tibia fracture fixation}

Using modelling and simulation in medical and biomechanical domains is very important as invasive investigations are avoided and suitable solutions are provided for reconstructing the damaged anatomical structures. The possibility of 3D representations of anatomical structures provides a valuable investigation method. By help of the multiple 2D images obtained from X-rays or CT scans, it is possible to create 3D representations using for example CATIA and create a model for a customized nail to be used in fixing the tibia fracture, like shown in fig.3.

*email: mindrescu.veronica@unitbv.ro; corina.ciupilan@yahoo.com; laurianfrancu@yahoo.com 


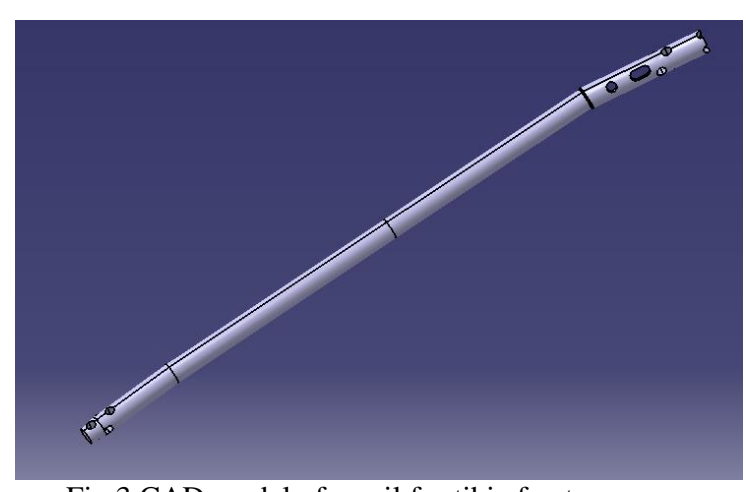

Fig.3 CAD model of a nail for tibia fracture

The next step is determining the resistance of the nail to mechanical loads using Finite Element Method (FEM) by dividing the whole in many very small parts (discretization) leading to simple forms for the finite elements of the structure. The real geometry is replaced by a network of finite elements following the real shape and the unknowns are determined only in the structure nodes (connections). The purpose of this analysis is to prove the maintaining of the structural integrity in the most severe conditions.

Modelling by help of finite elements method assumes two very important stages:

-Pre-processing includes modelling of geometric domain, modelling of material, creating the finite elements structure, modelling of constraints, modelling of loads and checking the finite elements model

-Post-processing means visualization and study of results, followed by model optimization.

The implant material was considered to be carbon fiber/PEEK (polyetheretherketone) polymer and the corresponding mechanical and thermal properties need to be set in the "Properties" option, that is: Young's modulus, Poisson's coefficient, density, coefficient of thermal expansion, flow limit.

It was considered that the main load is compression and according to the weight of the subject, the force acting upon the rod has different values. The calculus was made for a $60 \mathrm{~kg}$ subject and also for a 100kg subject. The knee joint supports around $85,6 \%$ of the body weight when the person is moving.

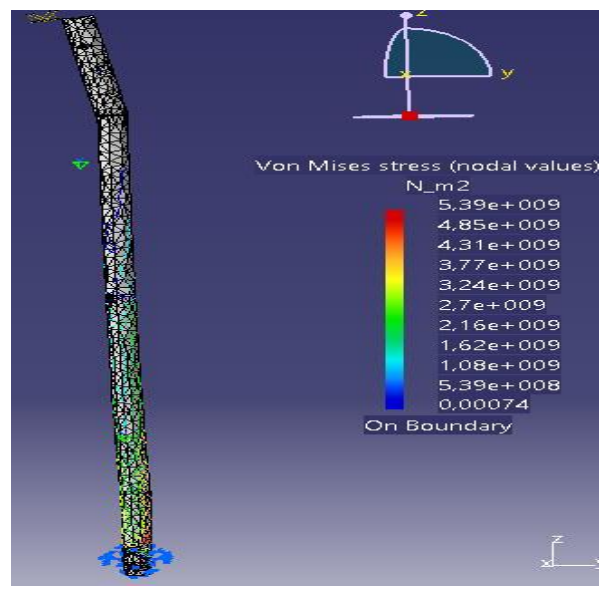

Fig.4 Von Mises stress tensor for 500N

There might be situations when the person is constrained to support the entire weight on a single foot so the implant should be able to resist to the whole value of the load. In this respect, for the $60 \mathrm{~kg}$ subject, the nail is subjected to a $500 \mathrm{~N}$ load while for the $100 \mathrm{~kg}$ subject the load represents more than $800 \mathrm{~N}$.The graphical representation of the efforts distribution due to statical loads, obtained for the first situation is presented in fig.4.

The equivalent von Mises stress tensor is determined by help of theory of breaking of maximum deformation energy. The relation for the equivalent stress is given by (1):

$$
\sigma_{e}=\frac{1}{\sqrt{2}} \sqrt{\left(\sigma_{x}-\sigma_{y}\right)^{2}+\left(\sigma_{y}-\sigma_{z}\right)^{2}+\left(\sigma_{z}-\sigma_{x}\right)^{2}+6\left(\tau_{x y}^{2}+\tau_{y z}^{2}+\tau_{x z}^{2}\right)}
$$

Analyzing fig. 4 it becomes obvious that the stress is higher in the lower area, so in order to determine the exact loads a detail will be studied, as shown in fig.5. In the most affected area the stress reaches 5,392.10 $\mathrm{MPa}$, while the minimum value is $3,594.10^{3} \mathrm{MPa}$. 


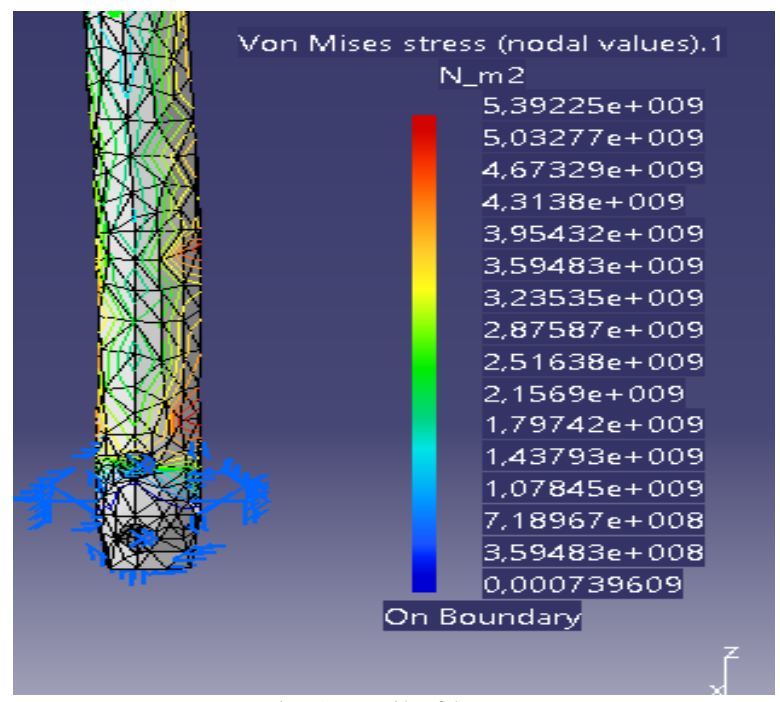

Fig.5 Detail of lower area

The stress distribution proves that the load is usually higher around the concentrators due to holes of various sizes required for fastening the screws and plates which tighten the assembly in its final form, but the material proves to be suitable from mechanical point of view.

\section{Rehabilitation methodology}

By its means, physical therapy fits perfectly into modern therapeutic conceptions, its efficiency being directly proportional to the shortening of the time required for recovery in the case of tibia fracture.

The physical therapy intervention includes a series of methods and techniques customized according to the symptomatology of the patients, having as objectives: the restoration of the field of movement as soon as possible, the improvement and the restoration of the muscular strength, of the joint mobility, the stability and the balance in the lower limb.

Kinetic treatment requires specific techniques of passive and active mobilization, the kinetic means having a positive impact on the muscle tone and circulation of the individual. In order to improve the articular amplitude, it is necessary to make the patient aware of the normal post-surgical amplitude, maintaining the kinesthetic memory by visualizing the passive limb [10]. In order to improve the muscular strength, it is necessary to act by the progressive hardening of the conditions for maintaining the positions or the execution of the movements. It is necessary to include in the recovery program the use of passive, active or active exercises with opposite resistance of objects, to train the muscle groups [11]. The therapeutic massage is another kinetic means indicated, but only the easy massage of the leg and foot, away from the place of production of the fracture that has the role of muscle relaxation. Including the physical therapy tools in the recovery program, they manage to shorten the recovery period (in the sense of shortening it), reduce the risk of complications and contribute to the consolidation of the positive results. Several prospective and comparative studies that explain the benefits of functional recovery, direct and indirect costs, increased quality of life in tibia fracture recovery are useful.The program of physiotherapy in the case of tibia fracture with the stem, begins, the day after the operation, according to the specific characteristics of the patient. The session begins with exercises in bed by activating the movement, gentle movements of the ankle and knee, supplemented, if necessary, with breathing exercises, lymphatic drainage (in case of significant swelling), massage or electrical stimulation of the muscles. The patient must learn to walk with the carts, not distributing only $10-20 \mathrm{~kg}$ on the operated side. After the surgical treatment, the indications for starting passive mobilization are extension at $0^{\circ}$ and flexion at $90^{\circ}$ of the knee. The patient cannot bear the weight on his foot for 3 months. Initially a flexion from $40^{\circ}$ to $60^{\circ}$ is allowed, after a week it is possible to increase up to $90^{\circ}$ flexion. [11]The walking distance increases gradually, for six weeks, the weight on the operated limb cannot be increased, which limits the variety of exercises applied in the recovery program. If the radiological control shows a good formation of the callus, the load continues to increase progressively until the end of the third month.After 3 months, the onset of total pregnancy progressively begins. The continuation of the recovery program is recommended to be done on fitness devices depending on the patient's mobility.From the 8th week: according to the radiological evolution, the surgeon can allow an increase of the pregnancy during the gait. From the 12th week, depending on the radiological evolution, one can go to the normal gait, in full load but progressively [12].

The therapeutic massage is another kinetic means indicated, but only the easy massage of the leg and foot, away from the place of production of the fracture that has the role of muscle relaxation. Including the kinetotherapeutic tools in the recovery program, they manage to shorten the recovery period (in the sense of shortening it), reduce the risk of complications and contribute to the consolidation of the positive results.Several prospective and comparative studies 
that explain the benefits of functional recovery, direct and indirect costs, increased quality of life in tibia fracture recovery are useful.

\section{Conclusions}

The failure of fixation implants might occur due to a faulty design or a deficient manufacturing, but the causes may vary from person to person. For this reason, in order to achieve a short healing period, it is recommendable to choose the nail following a thorough study of the injured person and adjust the device to their individual features. Also costs and biocompatibility are two important aspects that should be taken into consideration. Requirements are brilliantly met by PEEK polymers with the additional benefit that mechanical properties still can be tailored according to the individual features of the patient. The collaboration of physiotherapist, medical engineer and doctor is impetuously necessary, the article is based on the expertise and collaboration of the three fields.

\section{References}

1. ALBERT K, SCHLEDJEWSKI R, HARBAUGH M, BLESER S, JAMISON R, FRIEDRICH K., Characterization of wear in composite material orthopaedic implants. Part II: The implant/bone interface, Biomed Mater Eng. 1994;4(3):199-211

2. E.H. LEDET, B. LIDDLE, K. KRADINOVA, S.HARPER, Smart implants in orthopedic surgery, improving patient outcomes: a review, Innovation and Entrepreneurship in Health, Dovepress, 2019

3. S. M. KURTZ, J. N. DEVINE, PEEK Biomaterials in Trauma, Orthopedic, and Spinal Implants, Biomaterials. 2007 November ; 28(32): $4845-$ 4869

4. M. PRAKASAM, J. LOCS, K. SALMA-ANCANE, D. LOCA, A. LARGETEAU, L. BERZINA-CIMDINA, Biodegradable Materials and Metallic Implants-A Review, Journal of Functional Biomaterials, 2017, 8, 44

5. D. J. HAK, C. MAUFFREY, D. SELIGSON, B. LINDEQUE, Use of Carbon-Fiber-Reinforced Composite Implants in Orthopedic Surgery, The Cutting Edge, 2014, Volume 37, Number 12

6. D. W. S. N. LOUIS SOLOMON, Apley's System of Orthopaedics and Fractures, UK, 2010

7. PIĄTKOWSKI, K., PIEKARCZYK, P., KWIATKOWSKI, K. et al., Comparison of different locking plate fixation methods in distal tibia fractures, International Orthopaedics (SICOT) (2015) 39: 2245

8. R. MICLAUS, A. REPANOVICI, N. ROMAN, Biomaterials: Polylactic Acid and 3D Printing Processes for Orthosis and Prosthesis, Revista de Mat. Plast., 1, 2017

9.C.OPRAN, D. COTOROS, N. ROMAN, A. REPANOVICI, R. MICLAUS, Research Regarding the Impact Behaviour of Some Polymeric BioComposite Products for Orthopedic Use, Revista de MaterialePlastice, volume 3/2017

10. Z. PASZTAI, Kinetoterapiaînrecuperareafuncţională a aparatului locomotor, Oradea: EdituraUniversității, Oradea, 2001.

11. N. GORUN, Traumatologieosteoarticularăgenerală, Editura „CurteaVeche”, Bucureşti, 2011, p.3-52,

12. T. SBENGHE, BazeleTeoreticeși Practice ale Kinetoterapiei, București: Medicală,1999, p 105-106.

Manuscript received: 28.10 .2019 